Accepted manuscript version of the short communication „Reliability of chemical microanalyses for solid waste materials" by Ettler et al. (doi:10.1016/j.jhazmat.2012.04.015); The final paper has been published in Journal of Hazardous Materials (2012), Vol 221-222, 298-302 by 30 June 2012 and is accessible via http://dx.doi.org/10.1016/i.jhazmat.2012.04.015

(http://www.sciencedirect.com/science/article/pii/S0304389412003937)

\title{
1 Reliability of chemical microanalyses for solid waste materials
}

2

\section{Vojtěch Ettler ${ }^{1 *}$, Zdenek Johan ${ }^{2}$, Martina Vítková ${ }^{1}$, Roman Skála ${ }^{1,3}$, Marek Kotrlý ${ }^{4}$, Gerlinde Habler ${ }^{5}$, Mariana Klementová6}

1. Institute of Geochemistry, Mineralogy and Mineral Resources, Charles University in Prague, Faculty of Science, Albertov 6, 12843 Prague 2, Czech Republic (e-mail: ettler@natur.cuni.cz, fax.+420 221951496, telephone+420 221951493)

2. Bureau des Recherches Géologiques et Minières (BRGM), av. Claude Guillemin, 45060 Orléans, cedex 2, France

3. Institute of Geology of the Academy of Sciences of the Czech Republic, v.v.i., Rozvojová 269, 16500 Prague 6, Czech Republic

4. Institute of Criminalistics Prague, P.O. box 62/KUP, Strojnická 27, 17089 Prague 7, Czech Republic

5. Department of Lithospheric Research, University of Vienna, Althanstrasse 14, A-1090 Vienna, Austria

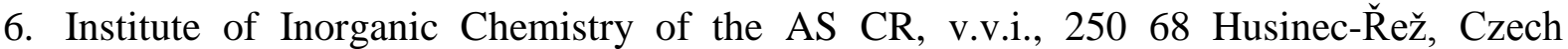
Republic

* corresponding author

\section{Abstract}

The investigation of solid speciation of metals and metalloids is required for accurate assessment of the hazardous properties of solid waste materials from high-temperature technologies (slag, bottom ash, fly ash, air-pollution-control residues). This paper deals with the problem of reliability of microanalyses using a combination of electron microprobe analysis (EPMA) and scanning electron microscopy (SEM) only. These methods do not permit to detect nanophases in host-crystals and lead to erroneous interpretation of analytical results, considering the elements of nanophases as belonging to the crystal structure of the main phase. More detailed analysis using transmission electron microscopy (TEM) on foils prepared by focused ion beam (FIB) can be used to solve this analytical problem. In this 
Accepted manuscript version of the short communication „Reliability of chemical microanalyses for solid waste materials“ by Ettler et al. (doi:10.1016/j.jhazmat.2012.04.015); The final paper has been published in Journal of Hazardous Materials (2012), Vol 221-222, 298-302 by 30 June 2012 and is accessible via http://dx.doi.org/10.1016/i.jhazmat.2012.04.015

(http://www.sciencedirect.com/science/article/pii/S0304389412003937)

1 study, lamellar aggregates of potassium-rich clinopyroxenes were detected in copper smelting

2 slags by a combination of SEM and EPMA. However, FIB-TEM indicated the presence of

3 leucite inclusions (tens to hundreds nm in size) within the clinopyroxene lamellae. Based on

4 examples from smelting slags and other solid waste materials, recommendations for standard

5 SEM and EPMA applications and the need for methods with higher resolution for

6 mineralogical investigation of waste materials are discussed.

8 Keywords: solid speciation, contaminants, electron probe microanalysis, FIB-TEM, slag

\section{Introduction}

11 The knowledge of detailed mineralogical and chemical com-positions of solid phases is

12 crucial for the assessment of hazardous properties in solid waste materials [1]. During the

13 past decade, an increasing number of papers has been devoted to mineralogical investigations

14 of waste materials from numerous high-temperature technologies, including metallurgical slags and mattes [2-13], bottom and fly ashes from municipal solid waste incinerators (MSWI) [14,15] or solid residues from sewage sludge gasification [16]. Scanning electron microscopy (SEM) coupled to energy dispersion spectrometry (EDS) and electron probe microanalysis (EPMA) are often used to determine the chemical compositions of various phases. The beam size of these techniques is generally close to $1 \mu \mathrm{m}$; however the volume of the analyzed material is generally in the range of several $\mu \mathrm{m}^{3}$ according to the analytical conditions (beam current and beam accelerating voltage) and the nature of the specimen [17].

22 The general formula of the clinopyroxene (Cpx) is M2M1T2O6, where $\mathrm{T}$ is a tetrahedral site occupied mostly by Si and Al, whereas other cations enter the M2 and M1 sites [18 and

24 references therein]. During our recent investigation of copper slags from the Zambian 
Accepted manuscript version of the short communication „Reliability of chemical microanalyses for solid waste materials“ by Ettler et al. (doi:10.1016/j.jhazmat.2012.04.015); The final paper has been published in Journal of Hazardous Materials (2012), Vol 221-222, 298-302 by 30 June 2012 and is accessible via http://dx.doi.org/10.1016/i.jhazmat.2012.04.015

(http://www.sciencedirect.com/science/article/pii/S0304389412003937)

1 Copperbelt [12], we noticed the presence of potassium-rich Cpx. Potassium with ionic radius

2 of $1.51^{\circ} \mathrm{A}[19]$ was thought to be too large to enter the Cpx structure at ambient pressures. At

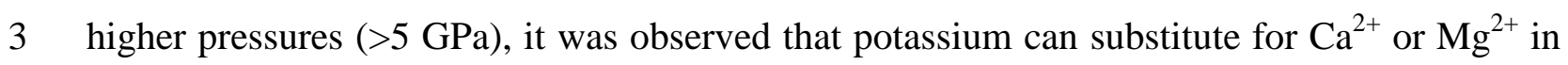

4 the M2 site [18], which is, however, not possible for slags produced at ambient pressures. In

5 this context, we carried out a more detailed study using a combination of other methods with

6 significantly higher spatial resolution (focused ion beam technique coupled to transmission

7 electron microscopy, FIB-TEM). Our data presented in this paper show how tricky the

8 chemical determinations of phases in solid wastes can be, with particular implications and

9 recommendations for the solid speciation of hazardous elements, such as metals and 10 metalloids.

\section{Experimental methods}

13 The slag samples came from the Nkana slag dumps in the Zambian Copperbelt (S1250'20',

14 E $\left.28^{\circ} 12^{\prime} 40^{\prime \prime}\right)$ and occurred as heavy and dense fragments up to $7 \mathrm{~cm}$ in size of black to gray color. The samples were prepared as polished thin sections for microscopic observation and electron probe microanalysis. A TESCAN VEGA scanning electron microscope equipped with an Oxford Link X-Max 50 energy dispersion spectrometer at Charles University in Prague (Czech Republic) was used for imaging and semi-quantitative chemical analyses.

19 Quantitative microanalyses were performed using a Cameca SX-100 electron microprobe 20 (EPMA) at the Institute of Geology, Academy of Sciences of the Czech Republic, Prague.

21 The following measurement conditions were used for the EPMA of silicate phases: accelerating voltage $15 \mathrm{kV}$, beam current $4 \mathrm{nA}$ (low current used to avoid volatilization of 23 alkalis), counting time $10 \mathrm{~s}$ and spot size $1 \mu \mathrm{m}$; standards used: jadeite, NaAlSi2O6 (Na,

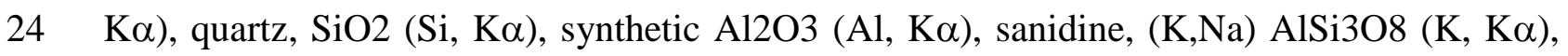


Accepted manuscript version of the short communication „Reliability of chemical microanalyses for solid waste materials“ by Ettler et al. (doi:10.1016/j.jhazmat.2012.04.015); The final paper has been published in Journal of Hazardous Materials (2012), Vol 221-222, 298-302 by 30 June 2012 and is accessible via http://dx.doi.org/10.1016/i.jhazmat.2012.04.015

(http://www.sciencedirect.com/science/article/pii/S0304389412003937)

1 diopside, CaMgSi2O6 (Ca, $\mathrm{K} \alpha$ ), rutile, TiO2 (Ti, $\mathrm{K} \alpha$ ), hematite, Fe2O3 (Fe, $\mathrm{K} \alpha$ ), $\mathrm{Mn} \mathrm{Cr}$

2 spinel, $\mathrm{MnCr} 2 \mathrm{O} 4(\mathrm{Cr}, \mathrm{K} \alpha)$, periclase, $\mathrm{MgO}(\mathrm{Mg}, \mathrm{K} \alpha)$, cobalt metal (Co, $\mathrm{K} \alpha)$. Empirical

3 formulae of Cpx were calculated on 4 cations per formula unit and the ferric and ferrous iron

4 contents were estimated assuming charge balance with 6 oxygens per formula unit. To verify

5 the presence of potassium in the Cpx at higher spatial resolution, three foils for transmission

6 electron microscopy (TEM) have been prepared using a FEI Quanta 3D FEG Dual Beam

7 focused ion beam (FIB) instrument at the Department of Lithospheric Sciences at the

8 University of Vienna (Austria). The instrument is equipped with a Field Emission Gallium

9 source. Platinum was used as deposition material for surface grounding and mounting the foil

10 onto a Cu-grid. Throughout the sputtering and deposition processes, the ion-beam

11 accelerating voltage was $30 \mathrm{kV}$, whereas successively lower beam currents (ranging from 50 $\mathrm{nA}$ to $30 \mathrm{pA}$ ) were used for progressive milling steps. Foils with dimensions of $17 \mu \mathrm{m} \times 10$

$13 \mu \mathrm{m} \times 2 \mu \mathrm{m}$ were cut with a well-defined orientation perpendicular to the Cpx-lamellae. The 14 foils were transferred to a Cu-grid by in-situ lift-out using an Omniprobe 100.7 micromanipulator. Then, the final thinning was performed stepwise using beam currents of 500 pA, 300 pA, 100 pA and finally 30 pA. The final thinned foil area was $13 \mu \mathrm{m} \times 9 \mu \mathrm{m}$ in size and 90-160 nm thick. For subsequent TEM investigations presented in this paper, we used the thinnest area located close to the center of foil \#2 with thickness close to $90 \mathrm{~nm}$. The TEM investigations on FIB-prepared foils were carried out on a JEOL JEM 3010 microscope operated at $300 \mathrm{kV}$ ( $\mathrm{LaB} 6$ cathode, point resolution $1.7^{\circ} \mathrm{A}$ ) with an attached Oxford Instruments energy dispersive X-ray spectrometer (EDS) at the Institute of Inorganic 22 Chemistry, Academy of Sciences of the Czech Republic. The images were recorded on a 23 CCD camera with resolution of $1024 \times 1024$ pixels using the Digital Micrograph software package. The EDS analyses were acquired and treated in the INCA software package. 
Accepted manuscript version of the short communication „Reliability of chemical microanalyses for solid waste materials“ by Ettler et al. (doi:10.1016/j.jhazmat.2012.04.015); The final paper has been published in Journal of Hazardous Materials (2012), Vol 221-222, 298-302 by 30 June 2012 and is accessible via http://dx.doi.org/10.1016/i.jhazmat.2012.04.015

(http://www.sciencedirect.com/science/article/pii/S0304389412003937)

1 Selected area electron diffraction (SAED) patterns were evaluated using the Process

2 Diffraction software package [20].

\section{$4 \quad 3$. Results and discussion}

5 Previous studies using powder X-ray diffraction analysis (XRD), EPMA and SEM

6 investigations indicated that $\mathrm{Cpx}$ and spinels were the predominant phases in the studied

7 slags, often associated with minor olivine-type phases and leucite [12]. Whereas Cpx and

8 olivines often formed large skeletal or harissitic crystals (up to several hundred $\mu \mathrm{m}$ in size),

9 leucite and spinels formed globular and well-delimited crystals, generally up to $100 \mu \mathrm{m}$ in

10 size [12]. In the slag sample, where K-Cpx was detected, Cpx forms approximately $1 \mathrm{~mm}$

11 wide, plume-shaped lamellar aggregates stacked in zones (Fig. 1a). Such spinifex textures

12 indicate the quenching of the slag melt and rapid crystallization of Cpx. Individual Cpx

13 crystallites were approximately 1-2 _m wide (Fig. 1b) and only larger lamellae were

14 selected for the EPMA analyses. The EPMA indicate that the Cpx crystallites are enriched in

$15 \mathrm{~K}$ (Table 1). The maximum $\mathrm{K}$ concentration in Cpx was $2.88 \mathrm{wt} \% \mathrm{~K} 2 \mathrm{O}$ (corresponding to

160.146 atoms per formula units, apfu) in the core of lamellae of the plume-like crystals (spot 2,

17 Fig. 1b). The EPMA of this KCpx yielded the formula

$\left(\mathrm{Ca}_{0.802} \mathrm{~K}_{0.146} \mathrm{Fe}^{2+}{ }_{0.030} \mathrm{Na}_{0.020}\right)_{\Sigma 1.000}\left(\mathrm{Fe}^{2+}{ }_{0.661} \mathrm{Fe}^{3+}{ }_{0.290} \mathrm{Mg}_{0.226} \mathrm{Al}_{0.100} \mathrm{Co}_{0.042} \mathrm{Ti}_{0.018}\right)_{\Sigma 1.000}\left(\mathrm{Si}_{1.742}\right.$

$\left.19 \mathrm{Al}_{0.258}\right)_{\Sigma 2.000} \mathrm{O}_{6.000}$

However, the FIB-TEM investigation showed that Cpx lamellae are intimately associated

21 with leucite (KAlSi2O6). Leucite inclusions of variable size (tens to hundreds of nm) and

22 Cpx-leucite inter-growths were not visible on the SEM images, but were detected by TEM coupled to EDS and SAED (Fig. 2). EDS spot analyses as well as X-ray elemental mapping 
Accepted manuscript version of the short communication „Reliability of chemical microanalyses for solid waste materials“ by Ettler et al. (doi:10.1016/j.jhazmat.2012.04.015); The final paper has been published in Journal of Hazardous Materials (2012), Vol 221-222, 298-302 by 30 June 2012 and is accessible via http://dx.doi.org/10.1016/j.jhazmat.2012.04.015

(http://www.sciencedirect.com/science/article/pii/S0304389412003937)

1 structure but is exclusively related to the associated leucite (Fig. 2). This study indicates that

2 EPMA analyses provided the chemical compositions of Cpx, which are flawed due to the

3 presence of nanometer-size solid inclusions and intergrowths with a K-rich phase (leucite),

4 not clearly detectable during the SEM and EPMA work, but only in FIB-TEM foils (Figs. 1

5 and 2). Although the areas selected for EPMA looked homogeneous and were larger than the

6 beam spot $(1 \mu \mathrm{m})$, small leucite solid inclusions undetected during standard SEM imaging

7 probably caused high $\mathrm{K}$ concentrations in the Cpx compositional data (Table 1). The leucite

8 inclusions may have been invisible in SEM images due to their small grain size or due to

9 their position immediately below the sample surface. In agreement with recently reviewed

10 data on K-bearing clinopyroxene [18], it is improbable that $\mathrm{K}$ can enter the Cpx structure at

11 ambient pressures. Our results have significant implications, especially for the determination

12 of chemical compositions of metal- and metalloid-bearing phases in hazardous waste materials. Standard SEM and EPMA have been routinely used in solid waste characterization over the past two decades. The recent literature contains a large number of papers showing how metals substitute for other cations in the crystalline phases and glass, which are often the predominant constituents of mineral solid wastes. In particular, numerous studies showed that glasses in smelting slags can contain significant amounts of metals. For example, Ettler et al.

18 [2] reported up to $3.72 \mathrm{wt} \% \mathrm{PbO}$ and $9.80 \mathrm{wt} \% \mathrm{ZnO}$ in a matrix glass from $\mathrm{Pb}$ slags from 19 Příbram, Czech Republic. Similarly, Piatak et al. [5] showed that interstitial glass in basemetal slags from smelting sites in the U.S.A. can contain up to $5.85 \mathrm{wt} \% \mathrm{PbO}$ and $4.16 \mathrm{wt} \%$

21 ZnO. However, it is not clear whether these analyses correspond to the actual glass compositions or whether the samples were contaminated by admixtures of metal-rich nanophases. This aspect is very frequent in glasses due to the immiscibility between silicate and sulfide liquids, leading to late solidification of the metal-rich fraction within the residual 
Accepted manuscript version of the short communication „Reliability of chemical microanalyses for solid waste materials“ by Ettler et al. (doi:10.1016/j.jhazmat.2012.04.015); The final paper has been published in Journal of Hazardous Materials (2012), Vol 221-222, 298-302 by 30 June 2012 and is accessible via http://dx.doi.org/10.1016/i.jhazmat.2012.04.015

(http://www.sciencedirect.com/science/article/pii/S0304389412003937)

1 glass. Another example of $\mathrm{Pb}$ smelting slag from Přibram (Czech Republic) is given to

2 illustrate the difficulties associated with the EPMA reliability in waste characterization (Fig.

3 3a and b). The SEM microphotograph in backscattered electrons (BSE) shows metallic

4 inclusions, significantly smaller than $1 \mu \mathrm{m}$, dispersed in glass (Fig. 3a and b). These can

5 affect the chemical composition of the glass when analyzed by EPMA. Similarly, Seignez et

6 al. [6] reported the presence of nanometer-scale phases $(<60 \mathrm{~nm})$ in glass from the $\mathrm{Pb}$ slag,

7 probably corresponding to Fe oxides (wüstite, FeO), and also stressed that SEM/EDS and

8 EPMA results must be interpreted with care. Consequently, these authors proposed the use of

9 methods with higher resolution (TEM) in order to understand the effects of these nanophases on the leaching of contaminants related to the glass dissolution and other weathering

11 processes [6,8]. The same feature is sometimes observed for crystalline phases. Indeed, 12 submicron metal- and metalloid-bearing inclusions were also observed by numerous 13 researchers within the early-crystallizing silicate and oxide phases [2,9,12] (see also Fig. 3a).

14 Although it is known that some substituting elements can enter the structure of crystalline phases (e.g. Zn, Cr, Cu in spinels [2,12,13,21], Zn and $\mathrm{Ni}$ in olivines [2,3,9,10] and Zn in melilite [2,9,21]), it is not clear, however, to what extent the EPMA results can be flawed by

17 the presence of nanophases. Melilite is known to contain high concentrations of $\mathrm{Zn}$, corresponding to the hardystonite end-member, Ca2ZnSi2O7 [21,22]. For example, in Znrich smelting slags from Poland, up to $23 \mathrm{wt} \% \mathrm{ZnO}$ was reported in melilites [7]. Nevertheless, Bindi et al. [22] used TEM for the high-resolution investigation of natural Zn-

21 rich melilite and found that the chemical composition in the sample can be slightly 22 inhomogeneous on a nanoscale, showing the presence of a modulated structure inducing 23 changes in diffraction patterns. Although small amounts of $\mathrm{Pb}$ are known to enter the melilite 24 structure [22], it is nevertheless difficult to ascertain whether the reported high $\mathrm{Pb}$ 
Accepted manuscript version of the short communication „Reliability of chemical microanalyses for solid waste materials“ by Ettler et al. (doi:10.1016/j.jhazmat.2012.04.015); The final paper has been published in Journal of Hazardous Materials (2012), Vol 221-222, 298-302 by 30 June 2012 and is accessible via http://dx.doi.org/10.1016/j.jhazmat.2012.04.015

(http://www.sciencedirect.com/science/article/pii/S0304389412003937)

1 concentrations in melilites from slags (up to $52.2 \mathrm{wt} \% \mathrm{PbO}$ [7]) correspond to substitution in

2 the crystal structure, and this is probably an artifact related to the presence of Pb-rich

3 nanophases. Investigation of secondary alteration products is even more complicated due to

4 the complexity of weathering processes occurring at the waste-water interface. For example,

5 Piantone et al. [15] reported that secondary calcite (CaCO3) from weathered MSWI bottom

6 ash can contain $0.82 \pm 0.43 \mathrm{wt} \% \mathrm{PbO}$ and up to $0.16 \pm 0.19 \mathrm{wt} \% \mathrm{ZnO}$. Using EPMA, it is

7 impossible to state whether these metals are incorporated into the calcite structure, adsorbed

8 on the calcite surface, or simply form nano-sized impurities rich in cerussite (PbCO3) or

9 smithsonite (ZnCO3) domains. Similarly, Bril et al. [23] studied the secondary alteration 10 products on the surface of $\mathrm{Zn}$ slags from Poland and reported EPMA with high 11 concentrations of $\mathrm{Zn}$ in anglesite (PbSO4), barite (BaSO4) and jarosite (KFe3(OH)6(SO4)2),

12 which could correspond either to solid-solutions in some cases or to physical impurities.

\section{Discussion and implications}

For mineralogical studies of solid waste materials, it is thus recommended that highresolution SEM imaging be performed using modes that visualize compositional heterogeneities and to use a SEM instrument with high resolution capability, such as a field emission gun (FEG)-SEM. If a standard SEM instrument is used, particular care with different contrast setting is recommended. Despite their size $(<1 \mu \mathrm{m})$ approaching the resolution limit of a standard SEM, it is relatively easy to visualize chemically contrasting entities trapped within the material with strikingly different mass (see e.g. metal-bearing droplets in silicate glass in Fig. 3a and b). In contrast, Fig. 3c and d shows more complicated

23 situations with dense metal-rich glass having similar brightness to other associated heavy phases (spinel in Fig. 3c and minute sulfide/metallic droplets in Fig. 3d). In these cases, 
Accepted manuscript version of the short communication „Reliability of chemical microanalyses for solid waste materials“ by Ettler et al. (doi:10.1016/j.jhazmat.2012.04.015); The final paper has been published in Journal of Hazardous Materials (2012), Vol 221-222, 298-302 by 30 June 2012 and is accessible via http://dx.doi.org/10.1016/i.jhazmat.2012.04.015

(http://www.sciencedirect.com/science/article/pii/S0304389412003937)

1 different contrast settings have to be consecutively employed to visualize all the phases

2 present. As shown in this study, for polyphase materials with grain sizes on a scale of a few

3 micrometers or less, the additional application of TEM, partly coupled to FIB sample

4 preparation, is required in order to obtain reliable compositional information. It is

5 nevertheless important to stress that artifacts of EPMA due to the limited spatial resolution

6 caused by an interaction volume of several $\mu \mathrm{m}^{3}$ in size can have a significant impact on

7 modelling of the overall hazardous properties of the particular waste material (e.g., long-term

8 leaching/release of contaminants) and, in justified cases, the solid speciation of contaminants

9 should be verified by other methods with higher resolution (e.g. FIB-TEM).

\section{Acknowledgements}

12 This study was supported by the Czech Science Foundation (GA ${ }^{\smile C R ~ 210 / 12 / 1413), ~ t h e ~}$

13 Ministry of Education, Youth and Sports of the Czech Republic (MSM 0021620855), the

14 Academy of Sciences of the Czech Republic (AV0Z30130516), the Austrian Science Fund 15 (FWF, project I471-N19) and Charles University Student Project (SVV 263203). A number of colleagues helped with the microprobe techniques: Dr. Radek Procházka and Dr. Martin Racek (SEM/EDS), ing. Anna Langrová (EPMA). Dr. Madeleine Štulíková is thanked for correction of the English in the manuscript. The reviews of three anonymous reviewers helped significantly to improve the original version of the manuscript. 
Accepted manuscript version of the short communication „Reliability of chemical microanalyses for solid waste materials" by Ettler et al. (doi:10.1016/j.jhazmat.2012.04.015); The final paper has been published in Journal of Hazardous Materials (2012), Vol 221-222, 298-302 by 30 June 2012 and is accessible via http://dx.doi.org/10.1016/i.jhazmat.2012.04.015

(http://www.sciencedirect.com/science/article/pii/S0304389412003937)

\section{References}

2 [1] P. Piantone, Mineralogy and pollutant-trapping mechanisms, C. R. Geosci. 336 (2004) $1415-1416$.

[2] V. Ettler, O. Legendre, F. Bodénan, J.C. Touray, Primary phases and natural weathering of old lead-zinc pyrometallurgical slag from Př́ibram, Czech Republic, Can. Mineral. 39 (2001) 873-888.

[3] A. Manasse, M. Mellini, C. Viti, The copper slags of the Capattoli Valley, Campiglia Marittima, Italy. Eur. J. Mineral. 13 (2001) 949-960.

[4] V. Ettler, Z. Johan, Mineralogy of metallic phases in sulphide matte from primary lead smelting, C. R. Geosci. 335 (2003) 1005-1012.

[5] N.M. Piatak, R.R. Seal II, J.M. Hammarstrom, Mineralogical and geochemical controls on the release of trace elements from slag produced by base- and precious-metal smelting at abandoned mine sites, Appl. Geochem. 19 (2004) 1039-1064.

[6] N. Seignez, A. Gauthier, D. Bulteel, M. Buatier, P. Recourt, D. Damidot, J.L. Potdevin Effect of Pb-rich and Fe-rich entities during alteration of a partially vitrified metallurgical waste, J. Hazard. Mater. 149 (2007) 418-431.

[7] J. Puziewicz, K. Zainoun, H. Bril, Primary phases in pyrometallurgical slags from a zinc-

[8] N. Seignez, A. Gauthier, D. Bulteel, D. Damidot, J.L. Potdevin, Leaching of lead metallurgical slags and pollutant mobility far from equilibrium conditions, Appl. Geochem. 23 (2008) 3699-3711. 
Accepted manuscript version of the short communication „Reliability of chemical microanalyses for solid waste materials“ by Ettler et al. (doi:10.1016/j.jhazmat.2012.04.015); The final paper has been published in Journal of Hazardous Materials (2012), Vol 221-222, 298-302 by 30 June 2012 and is accessible via http://dx.doi.org/10.1016/i.jhazmat.2012.04.015

(http://www.sciencedirect.com/science/article/pii/S0304389412003937)

1 [9] J. Kierczak, C. Néel, J. Puziewicz, H. Bril, The mineralogy and weathering of slag produced by the smelting of lateritic Ni ores, Szklary, southwestern Poland, Can. Mineral. 47 (2009) 557-572.

[10] V. Ettler, Z. Johan, B. Kř́́bek, O. Šebek, M. Mihaljevič, Mineralogy and environmental stability of slags from the Tsumeb smelter, Namibia, Appl. Geochem. 24 (2009) 1-15.

[11] V. Ettler, R. Červinka, Z. Johan, Mineralogy of medieval slags from lead and silver smelting (Bohutín, Př́ibram district, Czech Republic): Towards estimation of historical smelting conditions, Archaeometry 51 (2009) 987-1007.

[12] M. Vítková, V. Ettler, Z. Johan, B. Kř́bek, O. Šebek, M. Mihaljevič, Primary and secondary phases in copper-cobalt smelting slags from the Copperbelt Province, Zambia, Mineral. Mag. 74 (2010) 581-600.

[13] N.M. Piatak, R.R. Seal II, Mineralogy and the release of trace elements from slag from the Hegeler Zinc smelter, Illinois (USA). Appl. Geochem. 25 (2010) 302-320.

[14] P. Piantone, F. Bodénan, R. Derie, G. Depelsenaire, Monitoring the stabilization of municipal solid waste incineration fly ash by phosphation: mineralogical and balance approach, Waste Manage. 23 (2003) 225-243.

[15] P. Piantone, F. Bodénan, L. Chatelet-Snidaro, Mineralogical study of secondary mineral phases from wethared MSWI bottom ash: implications for the modelling and trapping of heavy metals, Appl. Geochem. 19 (2004) 1891-1904.

[16] A.B. Hernandez, J.H. Ferrasse, P. Chaurand, H. Saveyn, D. Borschneck, N. Roche, Mineralogy and leachability of gasified sewage sludge solid residues, J. Hazard. Mater. 191 (2011) 219-227.

[17] P.J. Potts, J.F.W. Bowles, S.J.B. Reed, M.R. Cave, Microprobe Techniques in the Earth Sciences, The Mineralogical Society series 6, Chapman \& Hall, London, 1995. 
Accepted manuscript version of the short communication „Reliability of chemical microanalyses for solid waste materials“ by Ettler et al. (doi:10.1016/j.jhazmat.2012.04.015); The final paper has been published in Journal of Hazardous Materials (2012), Vol 221-222, 298-302 by 30 June 2012 and is accessible via

http://dx.doi.org/10.1016/i.jhazmat.2012.04.015

(http://www.sciencedirect.com/science/article/pii/S0304389412003937)

1 [18] O.G. Safonov, L. Bindi, V.L. Vinograd, Potassium-bearing clinopyroxene: a review of experimental, crystal chemical and thermodynamic data with petrological applications, Mineral. Mag. 75 (2011) 2467-2484.

[19] R.D. Shannon, Revised effective ionic radii and systematic studies of interatomic distances in halides and chalcogenides, Acta Cryst. A32 (1976) 453-443.

[20] J.L. Lábár, Consistent indexing of a (set of) SAED pattern(s) with the Process Diffraction program, Ultramicroscopy 103 (2005) 237-249.

[21] A. Trujillo-Vazquez, H. Metiver-Pignon, L. Tiruta-Barna, P. Piantone, Characterization of a mineral waste resulting from the melting treatment of air pollution control residues, Waste Manage. 29 (2009) 530-538.

[22] L. Bindi, M. Czank, F. Röthlisberger, P. Bonazzi, Hardystonite from Franklin Furnace: a natural modulated melilite, Am. Mineral. 86 (2001) 747-751.

[23] H. Bril, K. Zainoun, J. Puziewicz, A. Courtin-Nomade, M. Vanaecker, J.C. Bollinger, Secondary phases from the alteration of a pile of zinc-smelting slags as indicators of environmental conditions. An example from Świętochłowice, Upper Silesia, Poland, Can. Mineral. 46 (2008) 1235-1248. 
Accepted manuscript version of the short communication „Reliability of chemical microanalyses for solid waste materials“ by Ettler et al. (doi:10.1016/j.jhazmat.2012.04.015); The final paper has been published in Journal of Hazardous Materials (2012), Vol 221-222, 298-302 by 30 June 2012 and is accessible via

http://dx.doi.org/10.1016/i.jhazmat.2012.04.015

(http://www.sciencedirect.com/science/article/pii/S0304389412003937)

Table 1. Representative electron microprobe analyses of plume-like clinopyroxenes (in wt\% of oxides) and empirical formulae calculated to 4 cations and 6 oxygens per formula unit.

\begin{tabular}{|c|c|c|c|}
\hline wt $\%$ & spot 2 & spot 23 & Range $(n=11)$ \\
\hline $\mathrm{SiO}_{2}$ & 43.73 & 44.54 & $43.15-44.54$ \\
\hline $\mathrm{TiO}_{2}$ & 0.59 & 0.61 & $0.54-0.7$ \\
\hline $\mathrm{Al}_{2} \mathrm{O}_{3}$ & 7.63 & 7.84 & $6.42-7.84$ \\
\hline $\mathrm{Cr}_{2} \mathrm{O}_{3}$ & $<\mathrm{DL}$ & $<\mathrm{DL}$ & $<$ DL-0.18 \\
\hline $\mathrm{FeO}$ & 19.35 & 18.87 & 18.54-21.94 \\
\hline $\mathrm{MgO}$ & 3.81 & 4.32 & $3.81-4.79$ \\
\hline $\mathrm{CoO}$ & 1.30 & 1.29 & $1.16-1.56$ \\
\hline $\mathrm{CaO}$ & 18.80 & 19.23 & $18.8-21.34$ \\
\hline $\mathrm{Na}_{2} \mathrm{O}$ & 0.27 & 0.15 & $<$ DL-0.27 \\
\hline $\mathrm{K}_{2} \mathrm{O}$ & 2.88 & 1.98 & $0.62-2.88$ \\
\hline Total & 98.36 & 98.83 & 98.36-100.9 \\
\hline \multicolumn{4}{|l|}{ T site } \\
\hline $\mathrm{Si}$ & 1.742 & 1.765 & $1.705-1.765$ \\
\hline${ }^{[4]} \mathrm{Al}$ & 0.258 & 0.235 & $0.235-0.295$ \\
\hline${ }^{[4]} \mathrm{Fe}^{3+}$ & n.d. & n.d. & n.d. \\
\hline \multicolumn{4}{|l|}{ M1 site } \\
\hline${ }^{[6]} \mathrm{Al}$ & 0.100 & 0.132 & $0.014-0.132$ \\
\hline${ }^{[6]} \mathrm{Fe}^{3+}$ & 0.290 & 0.178 & $0.177-0.328$ \\
\hline $\mathrm{Ti}$ & 0.018 & 0.018 & $0.016-0.021$ \\
\hline $\mathrm{Cr}$ & n.d. & n.d. & n.d.-0.006 \\
\hline Co & 0.042 & 0.041 & $0.037-0.050$ \\
\hline $\mathrm{Mg}$ & 0.226 & 0.255 & $0.226-0.283$ \\
\hline $\mathrm{Fe}^{2+}$ & 0.325 & 0.376 & $0.323-0.400$ \\
\hline \multicolumn{4}{|l|}{ M2 site } \\
\hline $\mathrm{Fe}^{2+}$ & 0.030 & 0.072 & $0.030-0.078$ \\
\hline $\mathrm{Ca}$ & 0.802 & 0.817 & $0.802-0.908$ \\
\hline $\mathrm{Na}$ & 0.021 & 0.012 & n.d.-0.021 \\
\hline K & 0.146 & 0.100 & $0.031-0.146$ \\
\hline
\end{tabular}


Accepted manuscript version of the short communication „Reliability of chemical microanalyses for solid waste materials“ by Ettler et al. (doi:10.1016/j.jhazmat.2012.04.015); The final paper has been published in Journal of Hazardous Materials (2012), Vol 221-222, 298-302 by 30 June 2012 and is accessible via http://dx.doi.org/10.1016/i.jhazmat.2012.04.015

(http://www.sciencedirect.com/science/article/pii/S0304389412003937)
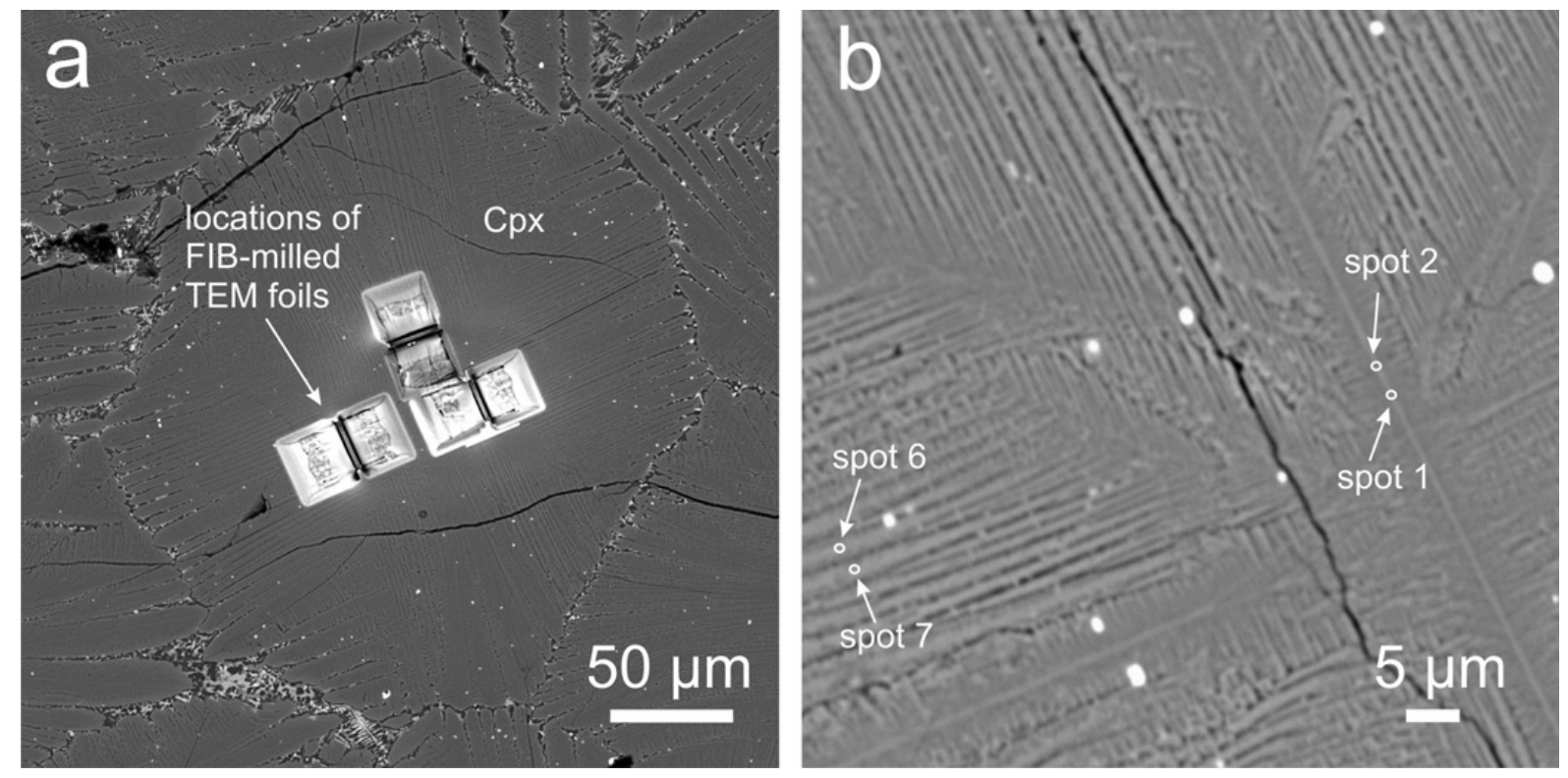

Figure 1. SEM-BSE (back scattered electron) images (a) of clinopyroxene (Cpx) plumes and (b) zoom on individual $\mathrm{Cpx}$ lamellae from the $\mathrm{Cu}$ smelting slag with location of several EPMA spots. 
Accepted manuscript version of the short communication „Reliability of chemical microanalyses for solid waste materials“ by Ettler et al. (doi:10.1016/j.jhazmat.2012.04.015); The final paper has been published in Journal of Hazardous Materials (2012), Vol 221-222, 298-302 by 30 June 2012 and is accessible via

http://dx.doi.org/10.1016/i.jhazmat.2012.04.015

(http://www.sciencedirect.com/science/article/pii/S0304389412003937)

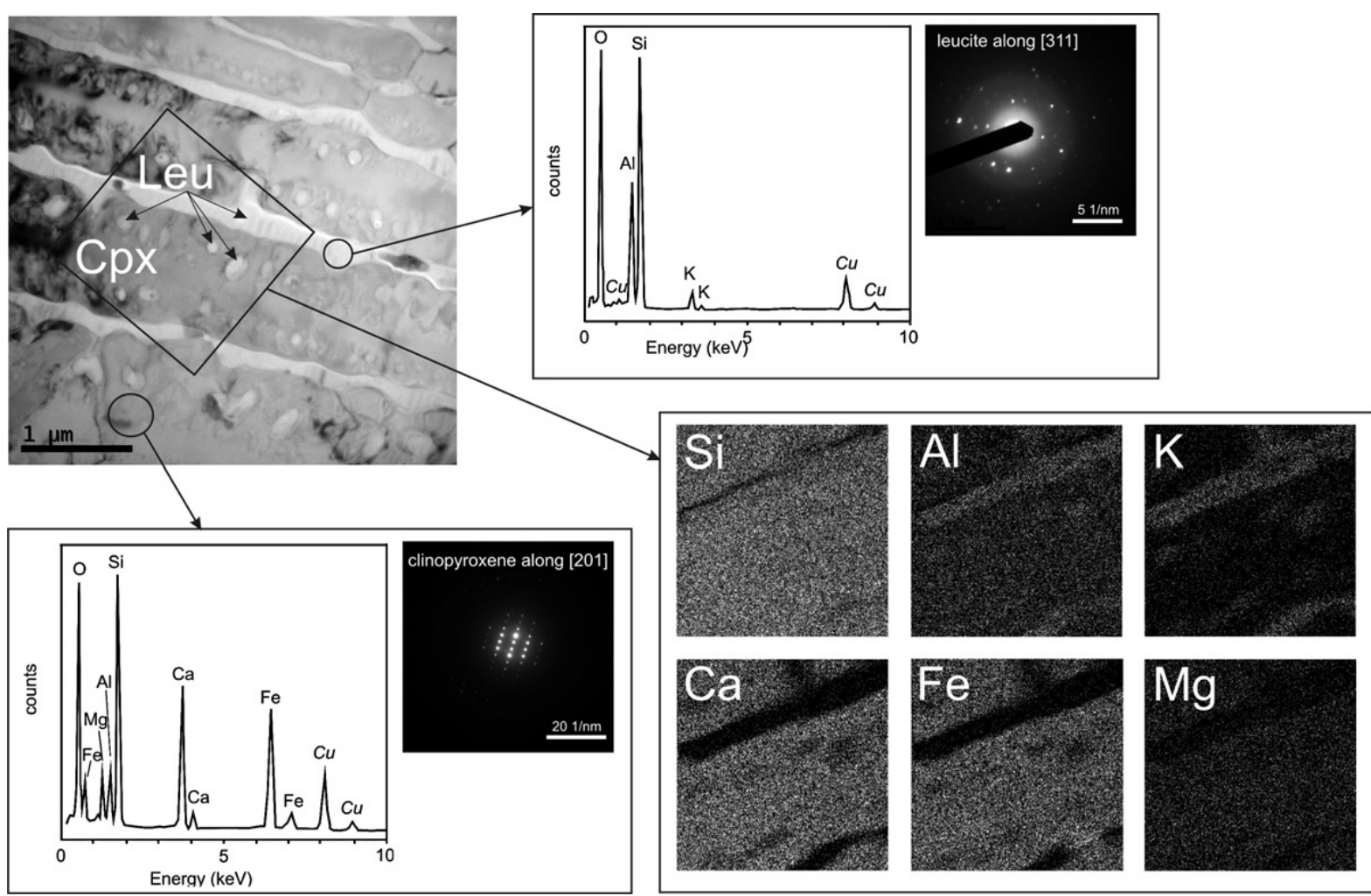

Figure 2. TEM image of the FIB-prepared foil oriented perpendicular to the Cpx lamellae. The presence of leucite (Leu) trapped within the Cpx can be discerned. The individual phases were identified by SAED and EDS (Cu given in italics, being present in the TEM grid); the $\mathrm{X}$-ray elemental maps show the spatial distribution of the major elements within a given zone. 

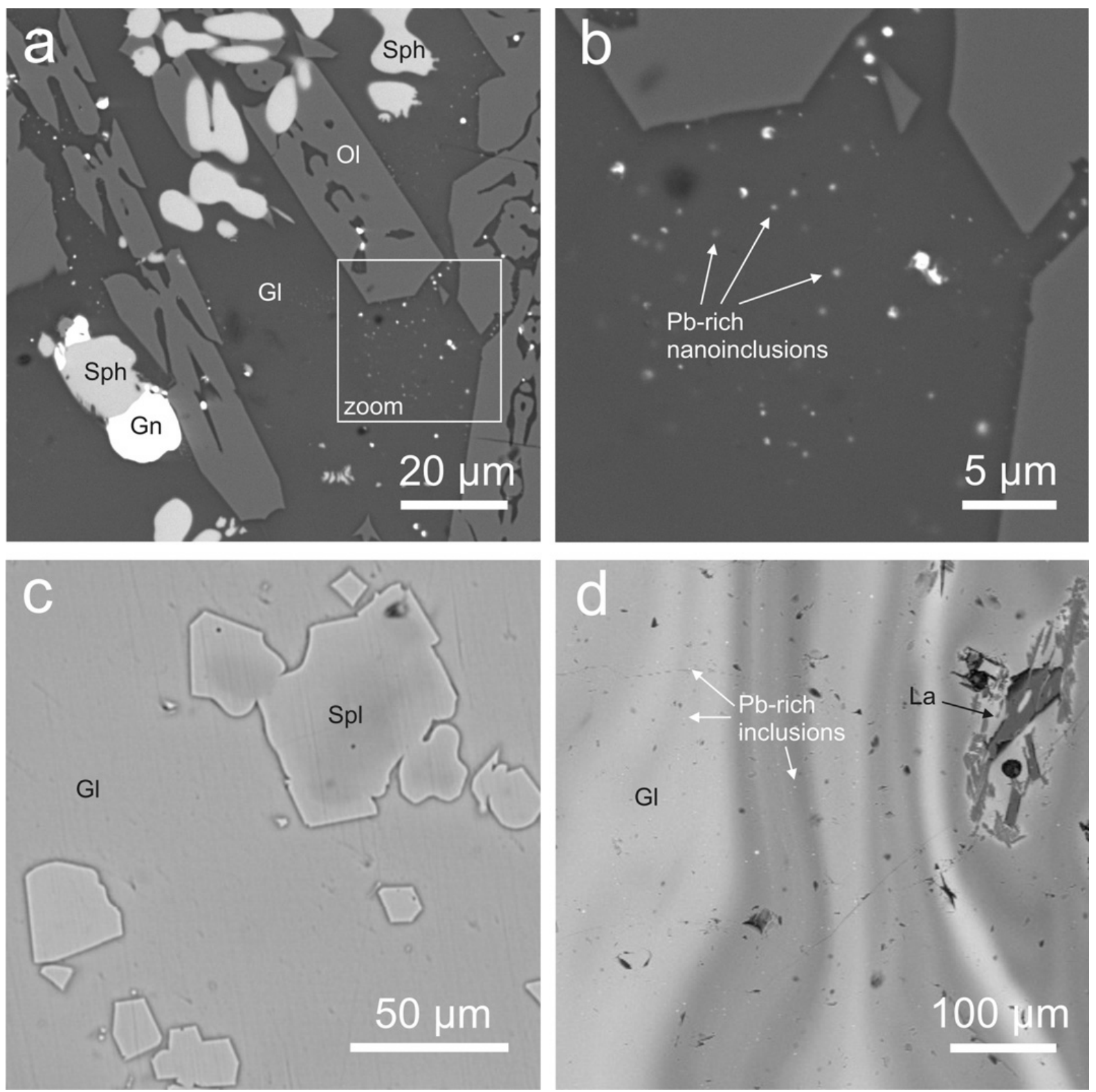

Figure 3. SEM-BSE images of the base-metal smelting slags. (a) Typical assemblage of $\mathrm{Pb}$ slag composed of olivine $(\mathrm{Ol})$, glass $(\mathrm{Gl})$, sphalerite $(\mathrm{Sph})$ and galena $(\mathrm{Gn})$ (slag from P`ríbram, Czech Republic); (b) zoom on a glassy zone with nano-sized Pb-rich inclusions, which can affect the reliability of EPMA analyses of the glass; (c) metal-rich glass (7.85 wt\% $\mathrm{PbO}, 9.12 \mathrm{wt} \% \mathrm{ZnO}, 1.78 \mathrm{wt} \% \mathrm{CuO}$ ) with similar contrast as spinels (Spl) (slag from Tsumeb, Namibia, adapted from [10]); (d) difficult setting of contrast in an SEM image of $\mathrm{Pb}$-rich glass (up to $33 \mathrm{wt} \% \mathrm{PbO}$ ) embedding small sulfide/metallic inclusions and associated to larnite, Ca2SiO4 (La) (medieval slag from an archaeological site in Prague, Czech Republic). 